\title{
O QUE É UMA REVOLUÇÃO?
}

Valerio Arcary, professor no IFSP

\section{RESUMO}

Na história e na vida não há mudança que não desperte oposição, não há luta que não encontre reação. Revolução e contrarrevolução são inseparáveis na história contemporânea. $\mathrm{O}$ argumento desta pesquisa é que revoluções devem ser compreendidas como um fenômeno histórico, ou seja, uma das formas de transformação da sociedades contemporâneas, que se precipitam quando fracassam as mudanças pela via das negociações. A sua característica definidora mais importante foi sempre a irrupção multitudinária das classes populares, e sua intervenção ativa na arena política: em outras palavras, a abrupta elevação da intensidade das lutas de classes. Por mais aguda que seja a crise econômica, por mais severas as seqüelas das catástrofes sociais, por mais dramática que seja a agonia de um regime político, sem que as massas entrem em cena, não se abre uma situação revolucionária. Uma revolução é um processo, não somente uma insurreição. E uma das características comuns às revoluções contemporâneas foi uma acelerada e intensa disputa pela direção, que leva à substituição vertiginosa de forças políticas à frente das massas em luta. Todas as revoluções começam como revoluções políticas (a luta pela derrubada de governos e regimes) e podem, na verdade, têm uma forte tendência à radicalização em revoluções sociais (a luta pela mudança das relações de propriedade). Revoluções não acontecem porque há revolucionários que as desejam. Organizações revolucionárias podem manter intensa atividade por décadas e permanecer, indefinidamente, marginais. Portanto, inofensivas. Um processo revolucionário só se abre quando a gravidade da crise social é tão grande que muitos milhões de pessoas, até então indiferentes aos destinos coletivos, despertam para a luta política.

\begin{abstract}
In history and in life there is no change that will not arouse opposition, no struggle that does not find reaction. Revolution and counterrevolution are inseparable in contemporary history. The argument of this research is that revolutions must be understood as a historical phenomenon, that is, one of the ways of transformation of contemporary societies, which precipitate when changes by negotiations fail. Its most important defining characteristic was always the outburst of popular classes and their active intervention in the political arena : in other words, the abrupt increase in the intensity of class struggles. However acute the economic crisis might be, for more severe the social disaster, no matter how long the agony of a political regime, if the masses do not come into the scene, a revolutionary situation is not open. A revolution is a process, not only as insurrection. And one of the common characteristics of contemporary revolutions was the intense and accelerated dispute over the leadership that leads to dizzying replacement of the organizations that are ahead of the masses fighting forces. All revolutions begin as political revolutions (the struggle to overthrow governments and regimes) and may, in fact, have a strong tendency to radicalization in social revolutions (the struggle for change in property relations). Revolutions do not happen because there are revolutionaries who desire them. Revolutionary tendencies can maintain intense activity for decades and remain indefinitely marginal. Therefore, stay harmless. A revolutionary process only opens when the gravity of the social crisis is so great that many millions of people, hitherto indifferent to collective destinies, awaken to political struggle.
\end{abstract}




\section{PALAVRAS-CHAVE}

História, revolução, reforma, crise,

\section{KEYWORDS}

History, revolution, reform, crisis.

No Manifesto Comunista, Marx e Engels ridicularizavam já o argumento liberal segundo o qual os comunistas faziam o jogo da reação conservadora. Durante a revolução de 1848 repetia-se, incansavelmente, que bastava que os patifes "socialistas" não tivessem lá estado para que os regimes constitucionais liberais se tivessem podido consolidar por toda a parte; os socialistas tinham feito medo à burguesia e tinham-na lançado nos braços da reação. Depois da Revolução Francesa, os conservadores, por seu lado, utilizaram um argumento semelhante contra os liberais; se não tivessem havido os excessos da Convenção e da Constituição "radical de esquerda" do ano II, a monarquia nunca teria sido restaurada (...) O conteúdo essencial destas teorias aparece claramente na tese segundo a qual a agitação radical dos «bolcheviques» forneceu a ocasião ou, pelo menos, uma desculpa ao fascismo para mobilizar as camadas amedrontadas e conservadoras da população: o fascismo é o castigo que a grande burguesia inflige ao proletariado pela sua agitação comunista. ${ }^{1}$

Ernest Mandel

O terreno das transformações históricas é sempre um campo de disputas que estão, por um longo período, mais ou menos dissimuladas, até que explodem de maneira vulcânica. As placas tectônicas da vida econômica e social estão ocultas embaixo do edifício de uma ordem política que parece estável. Não obstante, movem-se.

História deveria ser a investigação das mudanças na vida econômica, social e política. Estudar a transformação não deveria significar a desvalorização do que permanece, daquilo que é mais perene, que atravessa as longas durações. Porém, é a pulsação dos conflitos que pode atribuir interesse e sentido à narração do passado. Estes deslocamentos ora permitem o sucesso de reformas, pela via de conquistas/concessões, ora impõem o recurso à mobilização revolucionária. Enganam-se aqueles que denunciam as revoluções como responsáveis pela contrarrevolução, quando o que a história ensina é o contrário, nos recorda Mandel. Aqueles que definem revoluções somente a partir dos seus resultados confundem causas com consequências. Os resultados das revoluções nas sociedades industrializadas contemporâneas podem ser políticos ou sociais. ${ }^{2}$

\footnotetext{
1 MANDEL, Ernest, Sobre o Fascismo, Lisboa, Antídoto, 1976, p.38.

2 Revoluções políticas são aquelas que mudam o regime político, mas não alteram as relações sociais de produção. Elas consistem em mobilizações de massas que resultam essencialmente na mudança das formas (às vezes a substância mesmo) das instituições de Estado, na mudança de governo, sem que o domínio sobre o Estado seja deslocado do controle da classe dominante. Não é raro que revoluções políticas tragam consigo elementos de transformação econômico-sociais, mesmo quando o deslocamento do poder tenha sido feito entre fracções das classes dominantes e proprietárias. Na história não existem
}

\begin{tabular}{|l|l|l|l|l|}
\hline Rovista Dialectus & Ano 2 & n.5 & Agosto - Dezembro 2014 & p. 51 - 63 \\
\hline
\end{tabular}


Enganam-se, também, aqueles que engajados em suas preferências, só reconhecem como revoluções autênticas aquelas que tiveram direções que correspondem às suas escolhas ideológicas. Revoluções são processos muito complexos que não se definem somente a partir de uma variável. A presença de líderes muçulmanos à frente da revolução iraniana em Teerã não a diminui como uma luta de milhões contra a ditadura, somente explica o papel do clero xiita na disputa da direção da mobilização contra o Xá em 1979. A presença da Irmandade Muçulmana na Praça Tahrir do Cairo não diminui a representatividade dos que se levantaram contra a ditadura de Mubarak. A presença de fascistas nas barricadas na Praça Maidan de Kiev, não diminui o significado da revolução política ucraniana no final de 2013. Aliás, havia fascistas, também, nas mobilizações pró-Rússia na Criméia, ou no Leste da Ucrânia.

Os dois fatores indispensáveis de uma situação revolucionária têm sido a crise nacional e a disposição revolucionária das massas. Mas embora caminhem em paralelo, eles são desiguais e variáveis, e desenvolvem-se em proporções diferentes e, conforme a situação, um fator pode estar mais amadurecido do que o outro.

Mandel recuperou do esquecimento a potência deste conceito: foi sempre a impossibilidade de mudanças negociadas que abriu o caminho para irrupção de massas que denominamos de revolução. Revoluções como todos os processos históricos complexos só podem ser compreendidas considerando diferentes variáveis: (a) revoluções podem explicadas pelos seus fatores de impulso, ou seja, as forças motrizes históricas que repousam como as causas objetivas, a necessidade de drrubar ditaduras, defender a nação de agressão estrangeira, realizar a reforma agrária, conquistar a paz

processos "quimicamente puros". Mas o importante é desfazer um mal-entendido amplamente generalizado que não compreende que revoluções políticas são também revoluções de massas, ainda que delas não resulte uma mudança qualitativa na ordem econômico-social. Elas são, por outro lado, indivisíveis das lutas por reformas, como alertou Rosa Luxemburgo: A transformação socialista pressupõe uma luta demorada e persistente, sendo de todo provável que, no seu curso, seja o proletariado mais de uma vez rechaçado, e por tal forma a sua ascensão ao poder, da primeira vez, terá sido necessàriamente "cedo demais", do ponto de vista do resultado final da luta. Mas, em segundo lugar, a conquista "prematura" do poder de Estado pelo proletariado não poderá ser evitada, precisamente por isso, esses ataques prematuros do proletariado constituem um fator, e mesmo um fator muito importante na criação das condições políticas da vitoria final pelo fato de só no curso da crise politica que acompanhará a tomada do poder, no curso de lutas demoradas e tenazes, poder o proletariado chegar ao grau de maturidade política qne lhe permita obter a vitória definitiva da revolução.(...)Por conseguinte, uma vez que o proletariado não está em condições de apossar-se do poder político, a nao ser prematuramente, ou, em outras palavras, uma vez que é absolutamente forçado a apossar-se dêle uma ou varias vezes "cedo demais", antes de poder conservá-lo definitivamente, a oposição à conquista prematura do poder outra coisa nao é,, no fundo, que uma oposição, em geral, à aspiração do proletariado a apossar-se do poder." (grifo nosso) LUXEMBURGO, Rosa, Reforma e Revolução in Reforma, Revisionismo e Oportunismo, Rio de Janeiro, Laemmert, 1970, p.69/70.

\begin{tabular}{|l|l|l|l|l|}
\hline Qenista Dialectus & Ano 2 & n.5 & Agosto - Dezembro 2014 & p. 51 - 63 \\
\hline
\end{tabular}


quando de uma guerra, derrotar a exploraçãop dos trabalhadors, defender as conquistas da gerações anteriores, etc.; (b) revoluções têm sujeitos sociais protagonistas que podem ser variados: os assalariados urbanos nas sociedades urbanizadas, especialmente a classe operária industrial, os pequenos camponeses em sociciedades agrárias, as massas populares urbanas semi-proletárias, setores médios assalariados com alta escolaridade; (c) revoluções têm sujeitos políticos dirigentes, os paridos ou movimentos que conquistam legitimidade na representação de massas; (d) revoluções realizam transformações e têm resultados políticos e sociais: revoluções políticas derrubam governos, revoluções sociais destroiem as relações sociais dominantes.

Aqueles que reduzem a avaliação de uma revolução a somente uma das variáveis estão condenados a fazer, na melhor das hipóteses, análises insuficientes. Se olharmos somente os sujeitos políticos, portanto, superficialmente, pela direção, classificaremos a revolução portuguesa de 1974/75 como uma revolução do MFA ou militar, a iraniana como a revolução xiita, a nicaraguense como sandinista, o que sendo verdadeiro, todavia, parcial, induz ao erro. Todas as variáveis precisam ser consideradas.

Quais foram as causas, que classes e blocos de classe se aliaram para fazer a evolução, que organizações as dirigiram, quais foram os resultados? Todas estas variáveis merecem ser integradas em uma análise. Ainda assim a investigação não pode ignorar uma questão decisiva: contra quem lutaram? Quais eram os interesses que organizaram a contrarrevolução, qual era a sua natureza de classe, qual foi a sua estratégia política?

\section{Cinco hipóteses perigosas}

Comecemos pelo princípio. Ou seja, pelo esclarecimento do que não deve ser considerado, unilateralmente, para o entendimento do que é uma revolução. Encontraremos cinco teorias que expressam a permanência de preconceitos fortes na historiografia sobre o tema. O primeiro e mais reacionário remete ao clássico argumento da conspiração que afirma que revoluções não foram mais do que uma manipulação de massas por agitadores profissionais, invariavelmente, ao serviço de interesses inconfessáveis. Confundem-se neste raciocínio duas dimensões do problema teórico. Primeiro, perde-se a percepção do conflito em função do a priori de que mudanças poderiam e deveriam ter sido realizadas através de vias concertadas. Segundo, desqualificam-se os sujeitos sociais das revoluções, as classes interessadas na mudança,

\begin{tabular}{|l|l|l|l|l|}
\hline Qenista Dialectus & Ano 2 & n.5 & Agosto - Dezembro 2014 & p. 51 - 63 \\
\hline
\end{tabular}


em função do papel dos sujeitos políticos, as lideranças, os instrumentos de organização que pretendem representá-las.

Em todo o tipo de luta política, das mais simples às mais radicalizadas, estão presentes demagogos empenhados em se aproveitar das circunstâncias. O argumento parece poderoso, mas não é. Oportunistas e arrivistas não são senão a poeira da história. Por outro lado, a presença de revolucionários, ou seja, de uma vanguarda animada por um projeto de reorganização da vida social, pode ajudar ao triunfo de uma revolução, mas não explica porque aconteceu uma revolução. Revoluções precipitaram-se nas mais distintas sociedades, existissem ou não com antecedência revolucionários dedicados à sua preparação. A sua maior ou menor influência depende da existência de um processo revolucionário, e não o contrário.

A segunda teoria remete à questão da legalidade do exercício institucional do poder. É necessário recordar que uma revolução não se deve confundir com o triunfo de uma insurreição. Uma revolução política não é o mesmo que um golpe de Estado, quartelada ou putsch, embora a hora da insurreição militar possa precipitar ou decidir, no início ou ao final, o destino de um processo revolucionário. Revoluções são processos de participação popular tão ou mais autênticos, verdadeiros e representativos que eleições. Têm, portanto, uma legitimidade histórica irrefutável. ${ }^{3}$

\footnotetext{
${ }^{3}$ Não é porque algumas sociedades têm mais pressa de realizar transformações do que outras, ou porque alguns povos são mais aguerridos do que outros que revoluções acontecem. Revoluções são provocadas porque, em algumas circunstâncias raras, porém, não inusitadas, há crises sociais que se demonstram insolúveis. Diante das crises, as sociedades podem recorrer ao método da revolução, ou seja, a ruptura da ordem, ou ao método das reformas negociadas, portanto, da preservação da ordem com algumas concessões, para resolver as suas crises. Quando e porque prevalece um caminho ou outro é o cerne da investigação histórica. Em algumas etapas históricas, excepcionalmente, transformações progressivas foram possíveis através do jogo de pressões e concertações sociais e políticas. Foi assim, por exemplo, no final do XIX na Europa Ocidental, quando da repartição do mundo colonial consagrada pelo Tratado de Berlim de 1885. Porque era possível uma divisão de migalhas com os proletariados europeus com a elevação da pilhagem do mundo colonial e semicolonial, e porque existiu o medo de novas Comunas de Paris como em 1871. Ou entre 1945/75 na Tríade dos países centrais, EUA, Europa e Japão. Que só pode ser compreendida no contexto da terrível destruição da Segunda Guerra Mundial, da estruturação da etapa de paz armada entre os EUA e a URSS, pela preservação do domínio do mercado mundial, mesmo após as independências asiáticas e africanas e, por último, mas não menos importante, como medida preventiva diante da possibilidade de novas revoluções de outubro, como na Rússia em 1917. Regressões econômico-sociais reacionárias revelaram-se possíveis, também, através da celebração de acordos, sem a necessidade de recorrer à violência destrutiva contrarrevolucionária, como no Chile de Pinochet em 1973 ou na Argentina de Videla em 1976. Foi assim que a tempestade revolucionária que Portugal viveu em 1975 foi controlada após o 25 de novembro. Foi, também, assim na transição pós-Franco no Estado Espanhol em 1977/78. Mészaros esclarece: O capital, no século XX foi forçado a responder as crises cada vez mais extensas (que trouxeram consigo duas guerras mundiais, antes impensáveis) aceitando a "hibridização" sob a forma de uma sempre crescente intromissão do Estado no processo socioeconômico de reprodução como um modo de superar suas dificuldades, ignorando os perigos que a adoção deste re-
} 
A terceira teoria remete à ideia de que revoluções só foram possíveis em nações longínquas ou muito atrasadas, sendo processos bárbaros de luta contra regimes ditatoriais próprios de sociedades ainda em estágios primitivos de desenvolvimento econômico, social, cultural e político. Esta hipótese não corresponde à realidade histórica. Qualquer análise superficial permite concluir que situações prérevolucionárias ou diretamente revolucionárias convulsionaram nações entre as mais desenvolvidas como a França em 1968. Recordemos que a onda revolucionária que varreu a América Latina na primeira década do século XXI (Equador em 2000; Argentina em 2001; Venezuela em 2002; e Bolívia em 2003/2005) foi direcionada, inteiramente, contra governos eleitos nos marcos de regimes democrático-liberais, não contra regimes despóticos.

A quarta teoria remete ao argumento da miserabilidade, e defende que somente em condições de fome e pobrezas extraordinárias seria possível a eclosão de situações revolucionárias. Tampouco esta hipótese é defensável. Portugal em 1974/75 estava entre as nações em que a maioria da população tinha acesso a uma variada, rica e equilibrada dieta alimentar. A revolução na metrópole foi detonada pela revolução anticolonial na Guiné, Angola e Moçambique. Evidentemente, é verdade que a penúria favorece a instabilidade política, como ilustra a triste sequência de golpes militares na África subsaariana. Não obstante, não encontraremos correlação entre escassez e mobilização proletária e camponesa como pode confirmar o exemplo da Índia pós-independência, uma das sociedades em que a imensa maioria da população ainda sobrevive em condições de vulnerabilidade extrema.

A quinta hipótese é aquela que estabelece uma relação direta de causalidade direta entre guerra e revolução. A guerra foi, em inúmeras ocasiões (Alemanha, Áustria Hungria, Turquia em 1918), a antessala da revolução. Quando uma classe dominante convoca a nação para a guerra, com todos os imensos sacrifícios e suplícios que a guerra impõe, a hora da derrota pode coincidir com uma crise geral do Estado. No entanto, tampouco a derrota militar autoriza concluir que uma revolução se colocará, necessariamente, em marcha. A relação inversa, a revolução como antesala da guerra é, também, possível, mas não é inexorável.

médio traz a longo prazo, para a viabilidade do sistema. Mészáros István. A crise estrutural do capital, in Outubro 4, São Paulo, Xamã, Março de 2000, p.11.

\begin{tabular}{|l|l|l|l|l|}
\hline Rovista Dialectus & Ano 2 & n.5 & Agosto - Dezembro 2014 & p. 51 - 63 \\
\hline
\end{tabular}


Estas cinco hipóteses de interpretação demonstram-se, portanto, insustentáveis. Problemas históricos complexos como são as revoluções não devem ser simplificados pela adesão apaixonada a modelos teóricos fáceis. Injustiça e desigualdade assumiram as formas mais variadas em distintos países, e estiveram presentes como fatores de impulso de crises sociais graves. Todavia, crises sociais graves não são o bastante para explicar a explosão de revoluções. É necessário que muitos milhões cheguem à conclusão de que elas são insolúveis pela via das pressões e negociações.

Não é incomum, por último, que os meios de comunicação desqualifiquem a ocorrência de revoluções. Apoiam-se no senso comum que tem repulsa pela ideia de que, em circunstâncias excepcionais, o povo pode irromper na cena política através da ação direta. A maioria dos trabalhadores e da juventude nas sociedades contemporâneas, em situações de estabilidade política, não confia na força social de suas lutas. Revoluções são processos raros, por isso mesmo. Porque a força de inércia histórica mais poderosa é o medo. Aqueles que são vítimas da exploração ou da opressão duvidam muito da capacidade de unir suas forças, hesitam na hora de enfrentar, seriamente, seus inimigos de classe, e são cépticos sobre a chance da vitória. O que explica, em primeiríssimo lugar, o atraso da transformação social não é a conformidade das amplas massas com suas condições de vida. As massas populares resmungam, reclamam, e resistem o tempo todo. Mas não confiam em si mesmas, porque estão dilaceradas pelo receio, temor, horror do que podem ser as represálias dos ricos e poderosos. Em última análise, em um plano de abstração mais elevado, o medo da guerra civil contrarrevolucionária.

Não houve processo revolucionário que não tenha enfrentado reação e, sobretudo, resistência contrarrevolucionária. As forças interessadas na permanência da ordem estão em luta, permanentemente, contra os impulsos de mudança, porque têm interesses a preservar. O século XX e o XXI, época do apogeu e, hegelianamente, da decadência do capitalismo não foi imune a crises, mas as forças de inércia não foram menos poderosas. As concessões às reivindicações sociais das classes exploradas e oprimidas, mesmo quando foram articuladas no interior institucional dos regimes democráticos não foram feitas nunca sem muita luta, portanto, cedidas, preventivamente, pelo "grande medo" da "parteira" da história do século XX: a revolução. 
Revoluções acontecem porque transformações são necessárias, mas não quando foram necessárias. "Revoluções são impossíveis, até que são inadiáveis", cunhou Trotsky. A historiografia de inspiração liberal admite a relação, mas invertida, para concluir que as mudanças viriam, de qualquer forma, de maneira lenta e gradual e, possivelmente, mais indolor, não fossem os terremotos revolucionários, responsáveis pelas tempestades contrarrevolucionárias.

Esta interpretação é um argumento contrafactual insustentável. Sem as revoluções do século XX não se pode compreender, em alguns países, nem a existência do ensino público, nem a conquista da saúde universal, nem a previdência social, nem o salário mínimo, nem a redução da jornada de trabalho. Reformas foram possíveis porque existiu o medo de novas revoluções.

\section{O terrível atraso das transformações que não acontecem}

O que merece ser destacado para explicar a deflagração de uma situação revolucionária, em primeiríssimo lugar, foi o terrível atraso das mudanças que não vieram por reformas. Na história não há parto sem dor. Sem esse atraso, não há como compreender o que aconteceu na Tunísia, e incendiou a Praça Tahrir no Cairo em 2011, e inflamou as esperanças na Líbia, no Yemem, no Bahrein, ou na Síria.

Essa espera suspensa no tempo foi a expectativa de que reformas, mais ou menos indolores, poderiam acontecer. Quando fica claro que as promessas eram ilusões, tudo se acelera. As condições que fermentaram as revoluções nas sociedades contemporâneas foram as mais variadas, mas podemos discernir algumas constantes.

Quando uma sociedade descobre que os antagonismos econômicos, sociais e políticos se exacerbaram até o limite do que a ordem pode suportar, se abrem, grosso modo, dois caminhos. Das duas, uma: ou a transformação assume a forma de reformas preventivas, o que exige negociações políticas, concessões econômicas e compromissos sociais, ou as lutas de classes se agudizam em tal grau de intensidade que a vaga de choque da revolução é inescapável.

Nem os "brandos costumes" de um povo - como sugeriu Alexandre Herculano como chave da História de Portugal - ou a "cordialidade" - a inspirada hipótese de Sérgio Buarque de Hollanda para compreender as especificidades do Brasil - são suficientes como explicação de porquê, em algumas circunstâncias, as reformas

\begin{tabular}{|l|l|l|l|l|}
\hline Qenista Dialectus & Ano 2 & n.5 & Agosto - Dezembro 2014 & p. 51 - 63 \\
\hline
\end{tabular}


pactuadas ou as transições negociadas foram possíveis. Nem são, tampouco, os temperamentos "exaltados" de outros povos que poderiam esclarecer as revoluções que fizeram.

O padrão histórico contemporâneo atesta, indiscutivelmente, que revoluções se precipitam quando as transformações negociadas fracassaram. Quando a força obtusa da reação mantém a dominação tirânica, e a exploração econômico-social muito tempo além do que seria admissível, ou tolerável, uma revolução política se coloca em movimento. E a revolução política tem sido a antecâmara da revolução social.

Foi assim na Rússia em 1917, na Alemanha em 1918, na Espanha nos anos trinta, na Itália e França em 1943, ou na China em 1949, ou ainda em Cuba em 1959. Não foi diferente na Nicarágua ou no Irã em 1979, ou na Polônia em 1980, na Argentina em 1982, no Brasil em 1984. A contenção política de conflitos insolúveis sem mudanças tem limites históricos. ${ }^{4}$

\section{A revolução como uma urgência de futuro}

Sejamos precipitados, e encaremos o problema de frente. Já foi dito, por quem não gosta de História, que se nada muda, então nada importa. As concepções de História não são imunes à força avassaladora das premissas que uma ou outra visão do mundo estabelece a priori: as respostas que se encontram dependem das perguntas que são feitas. Por exemplo, se o foco da investigação se desloca para o que não muda, e tem perenidade, então é inexorável que o cepticismo triunfe sobre a vontade.

As possibilidades da mudança precisam ter dimensões humanas para que a desesperança não seja exasperadora: por isso, a contribuição primeira do marxismo para a História tem sido a oferta de uma explicação para a alternância de ritmos das transformações - acelerações e desacelerações - na vida das civilizações e sociedades. A

\footnotetext{
${ }^{4}$ A aflição, a irritação, a inquietação de dezenas de milhões não pode ser, indefinidamente, ignorada. O medo da luta coletiva, esse sentimento político tão poderoso, responsável pela manutenção da ordem, desmorona diante de um medo maior: o medo de que a vida não mude. A exacerbação da luta de classes explode na irrupção das amplas massas populares, até então, inativas. Os limites de tempo podem ser, exasperadamente, longos para a extensão de uma vida humana, mas são na escala da história, incontornáveis. É o que nos recorda Bensaïd, ao contextualizar Lenine: A elaboração desta problemática ao longos dos anos da guerra e a oposição consciente à ortodoxia reinante estão articuladas em Lenine à releitura da Lógica de Hegel. Desde 1915 ele rumina o conceito de crise revolucionária que o obceca ao longo de todo o ano decisivo de 1917. (tradução nossa) BENSAÏD,Daniel Le pari mélancolique: métamorphoses de la politique, politique des métamorphoses. Paris, Fayard, 1997.p78/9.
}

\begin{tabular}{|l|l|l|l|l|}
\hline Qenista Dialectus & Ano 2 & n.5 & Agosto - Dezembro 2014 & p. 51 - 63 \\
\hline
\end{tabular}


defesa de um fundamento econômico-social para os conflitos políticos não diminuiu o significado da luta de ideias. Somente permitiu oferecer uma interpretação distinta, mais minuciosa e articulada, para as formas que assumiu a mudança das relações sociais e políticas.

Historiadores devem ser capazes de se perguntar, seja qual for o período a que sua investigação se dedique, quais eram os desafios que os homens que a fizeram se colocaram. Como se formularam as alternativas que os dividiam e, finalmente, porque uma via se sobrepôs a outras e, em que medida a aventura da mudança foi aberta ou bloqueada. Nesse contexto adquire importância o conceito de revolução.

Mas é preciso não esquecer que se, por necessidade de análise, pensamos as revoluções em termos de causa e efeito como fenômenos nacionais, é preciso ter claro que os efeitos são, também, causas, e que elas estão inseridas em um processo mundial. A revolução portuguesa de 1974, por exemplo, é incompreensível se a análise do 25 de Abril não for contextualizada pela revolução africana de libertação nacional.

\section{Mudanças por reformas e mudanças por revolução: por quê?}

Injustica e tirania, em graus variados de intensidade, governam o mundo. Se considerarmos um grau de abstração muito elevado para a análise, toda e qualquer sociedade está, continuamente, diante da necessidade de resolver, em maior ou menor medida, os conflitos que resultam tanto da sua inserção no mercado mundial, da disputa de posições entre Estados, quanto das lutas sociais que as dividem, destroçam, despedaçam, e até desintegram. Se não o fizerem mergulham em estagnação. A estagnação econômica e social é o caminho da decadência nacional. Indivíduos podem renunciar à defesa de seus interesses. As classes, todavia, não cometem suicídio histórico. A destruição de uma nação não pode ser feita sem que haja violenta resistência. A decadência nacional pode demonstrar-se irreversível, mas haverá luta revolucionária. ${ }^{5}$

\footnotetext{
${ }^{5}$ Todas as revoluções estabelecem novas referências teóricas e novos paradigmas históricos. Nunca poderá existir uma teoria da revolução acabada, porque cada processo acrescenta novos elementos, confirma, de alguma maneira, as conclusões anteriores, porém, contraria outras. A mais elaborada e complexa teoria será sempre um esquema provisório diante de uma realidade imprevisível, não por ausência de causalidades, mas por excesso. Em suma, revoluções surpreendem. Em primeiro lugar, porque a luta de classes é um processo pleno de incertezas, e sempre em aberto, em que as semelhanças e recorrências, mesmo quando presentes e importantes, não podem anular as alargadas margens de originalidade histórica inerentes a cada processo. Lembrando o alerta de Pierre Vilar: "Resta considerarmos que um regime social não está constituido exclusivamente por seus fundamentos econômicos. A cada modo de produção corresponde não somente um sistema de relações de produção, como também um sistema de direito, de instituições e de formas de pensamento. Um regime social em
} 
A solução dos conflitos exige, portanto, mudanças. Esta necessidade foi mais ou menos intensa em função de muitas circunstâncias. O que impera em sociedades desiguais foi, todavia, a força de inércia dos interesses dos dominantes. A exploração, o abuso, a opressão tenderam a perpetuar-se. Quando prevaleceu a prosperidade social e o crescimento econômico, transformações na forma de pressões, embora tenham exigido organização e disposição de luta foram menos difíceis.

Transformações econômico sociais podem assumir a forma de reformas ou de revoluções. Não obstante, nação alguma pode escolher, livremente, se prefere que as mudanças sejam realizadas por formas mais negociadas ou menos conflitivas, mais conciliadas ou menos turbulentas. A humanidade faz a sua própria história. Mas uma humanidade dilacerada por terríveis divisões de interesses constrói o seu destino por caminhos onde a margem de escolhas foi dramaticamente estreita, através de combates cujos desenlaces eram imprevisíveis, e por vias que independiam da vontade de seus líderes.

Em determinadas épocas, quando que uma formação social é progressiva, ou seja, em que as relações de produção dominantes permitem, ou até impulsionam o progresso social, as reformas garantem alterações, aperfeiçoam mudanças e legitimam transformações e, portanto, favorecem a conservação da ordem social. Quando existem margens de mobilidade social elásticas, ainda que a ordem social seja infame, a possibilidade de reformas permite a preservação da estabilidade política.

É somente quando as reformas não são mais possíveis, é somente quando as classes dominantes são incapazes de fazer concessões que as classes dominadas são empurradas no caminho da revolução. Qual é o limite de expansão de uma determinada ordem econômico-social? Quando se manifesta o esgotamento de um determinado modo de produção? Esse é, justamente, o centro do debate de caracterização da natureza histórica da época. Lenin realizou uma síntese que ficou clássica:

A lei fundamental da revolução, confirmada por todas as revoluções, e em particular, pelas três revoluções russas do século $X X$, consiste no seguinte: para a revolução não basta que as massas exploradas e oprimidas tenham consciência da impossibilidade de continuar vivendo como vivem e exijam mudanças; para a revolução é necessário que os exploradores não possam continuar vivendo e governando como vivem e governam.

decadência serve-se precisamente deste direito, dessas instituições e desses pensamentos já adquiridos, para opor-se com todas suas forças às inovações que ameaçam a sua existência. Isto provoca a luta das novas classes, das classes ascendentes, contra as classes dirigentes que ainda acham-se no poder (...) $O$ regime feudal não morreu sem defender-se." VILAR, Pierre. "A transição do Feudalismo ao Capitalismo" In SANTIAGO, Theo Araujo. Capitalismo Transição. Rio de Janeiro, Eldorado, 1974. p. 47. 
Só quando "os de baixo" não querem e os "os de cima" não podem continuar vivendo como antes, só então pode triunfar a revolução. (grifo e tradução nossos) ${ }^{6}$

Esta definição de Lênin para crise revolucionária, escrita depois de Outubro, destaca a necessidade da crise das classes dominantes como condição para o triunfo da revolução.

A maioria das crises revolucionárias dos últimos quarenta, entretanto, se distinguiu do período histórico anterior (1917/1937) e posterior à Segunda Guerra Mundial (1945/1975), pela inexistência de organismos de poder popular que tenham evoluído para um grau de centralização nacional em alternativa ao poder de Estado. Nenhuma delas radicalizou no sentido de uma revolução econômico-social que fosse além da propriedade privada e do mercado.

Depois da derrota norte-americana no Vietnam em 1973, ou seja, nos últimos quarenta anos, só triunfaram revoluções políticas. Em outras palavras, nenhuma revolução avançou até à ruptura com o capitalismo. Ainda que tenham ocorrido impressionantes revoluções populares, com um engajamento massivo de milhões de pessoas na luta pelas suas reivindicações, situações de duplo poder, desmoronamento de regimes e governos, em nenhum desses processos, se repetiu a experiência da expropriação da propriedade privada.

A queda de ditaduras bonapartistas, as revoluções políticas democráticas das últimas décadas, embora muito desiguais entre si, umas mais radicalizadas (Chile 1972/73, Portugal 19747/75), outras menos, estagnaram sem exceção na estação da derrubada de ditaduras. Em alguns desses processos, a força do impulso revolucionário inicial foi tão poderoso que os atos seguintes da revolução chegaram a ameaçar a estabilidade das classes burguesas durante alguns anos. Mas a revolução se afogou nos limites dos novos regimes democrático-liberais.

O padrão que prevaleceu de revoluções políticas, mesmo quando profundas e raduicalizadas, é que não abriram o caminho para levar ao poder governos que se apoiassem na mobilização de massas para alterar as relações sociais. Quarenta anos já constituem um intervalo histórico significativo. O que exige uma reflexão e explicação teórica. A hipótese mais prometedora é aquela que destaca os limites do substitucionismo social. Revoluções sociais ficaram mais difíceis porque: (a) uma

\footnotetext{
${ }^{6}$ LENIN, Vladimir Ilitch Ulianov, La maladie infantile du communisme (Le Gauchisme), Pekin, Editions en langue etrangéres, 1970, parte IX, p.85.
} 
dinâmica anticapitalista é mais fácil de ser interrompida quando diminui o protagonismo proletário; (b) a contrarrevolução aprendeu as lições da história mais rapidamente do que o movimento dos trabalhadores.

\section{Referências}

ANDERSON, Perry. Considerações sobre o Marxismo Ocidental. Trad. Carlos Cruz. Porto, Afrontamento, 1976. (Crítica e sociedade 10).

BERNSTEIN, Eduard. Las premisas del socialismo y las tareas de la socialdemocracia: problemas del socialismo; el revisionismo en la socialdemocracia. Trad. Irene del Carril e Alfonso García Ruiz. México, Siglo XXI, 1982.

BENSAÏD, Daniel. La discordance des temps: essais sur les crises, les classes, l'histoire. Paris, Éditions de la Passion, 1995

DRAPER, Hal. Karl Marx's theory of revolution: The theory of the state. New York and London, Monthly Review Press, 1978. (vol. I e II).

ENGELS, Friedrich. "Les journées de juin 1848" in MARX, Karl. Les luttes de classes en France. Paris, Editions Sociales, 1970.

KAUTSKY, Karl. O caminho do poder. Trad. Moniz Bandeira. São Paulo, HUCITEC, 1979.

LOWY, Michael. La teoría de la revolución en el joven Marx. Trad. Francisco Gonzalez Aramburu. Argentina, Siglo Veintiuno Argentina Editores,1972.

LUKÁCS, György. O pensamento de Lenine. Trad. Luís Campos. Lisboa, Dom Quixote, 1975.

LUXEMBURGO, Rosa. Reforma ou revolução? Trad. Manuel Augusto Araújo. $3^{a}$ ed. Lisboa, Estampa, 1974.

A crise da social-democracia. Trad. Maria Julieta Nogueira e Silvério Cardoso da Silva. Lisboa, Presença; Brasil, Martins Fontes, 1974.

MARX, Karl. As lutas de classes na França (1848-1850). São Paulo, Global, 1986. (Coleção Bases 49). 